\title{
BMJ Open Examining the mediating effect of work- to-family conflict on the associations between job stressors and employee psychological distress: a prospective cohort study
}

Takashi Oshio, ${ }^{1}$ Akiomi Inoue, ${ }^{2}$ Akizumi Tsutsumi ${ }^{2}$

To cite: Oshio T, Inoue A, Tsutsumi A. Examining the mediating effect of work-to-family conflict on the associations between job stressors and employee psychological distress: a prospective cohort study. BMJ Open 2017;7:e015608. doi:10.1136/ bmjopen-2016-015608

- Prepublication history for this paper is available online. To view these files please visit the journal online (http://dx.doi. org/10.1136/bmjopen-2016015608).

Received 20 December 2016 Revised 7 June 2017 Accepted 8 June 2017

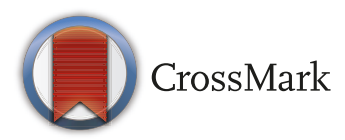

${ }^{1}$ Institute of Economic Research Hitotsubashi University, Kunitachi, Tokyo, Japan ${ }^{2}$ Department of Public Health, Kitasato University School of Medicine, Sagamihara, Japan

Correspondence to Dr. Takashi Oshio; oshio@ier.hit-u.ac.jp

\section{ABSTRACT}

Objectives The mediating effect of work-to-family conflict (WFC) on the associations between eight types of job stressors (measured based on the job demandscontrol, effort-reward imbalance and organisational justice models) and psychological distress in employees was examined.

Design This study employed a prospective design. Setting An occupational cohort study in Japan (Japanese Study of Health, Occupation, and Psychosocial Factors Related Equity; J-HOPE).

Participants 5859 men and 1560 women who were working for 11 firms and participated at three consecutive waves of J-HOPE, at 1-year intervals, from 2010 to 2013. Main outcome measures Psychological distress, as measured by Kessler 6 scores.

Results Mediation analysis using data on job stressors at baseline, WFC at 1-year follow-up and psychological distress at 2-year follow-up showed that WFC mediated $39.1 \%(95 \% \mathrm{Cl} 29.1 \%$ to $49.1 \%)$ and $44.5 \%(95 \% \mathrm{Cl}$ $31.4 \%$ to $51.7 \%$ ) of the associations of psychological distress with job demands and effort, respectively, for men. The mediating effect of WFC was smaller for job stressors indicating reduced job resources, compared with job demands and effort. The mediating effect of WFC was somewhat larger for women than it was for men, with WFC mediating $47.5 \%(95 \% \mathrm{Cl} 22.5 \%$ to $72.6 \%)$ and $64.0 \%(95 \% \mathrm{Cl} 24.3 \%$ to $100.0 \%)$ of the associations of psychological distress with job demands and effort, respectively.

Conclusions WFC was a key mediator in the associations between most job stressors and employee psychological distress. Results suggest that policy measures and support from supervisors, to prevent job stressors from adding to WFC, are needed to reduce employee psychological distress.

\section{INTRODUCTION}

The association between adverse work characteristics and the health outcomes of employees has been a key issue in occupational health research. Some well-established models provide theoretical grounding for this
Strengths and limitations of this study

- A large-scale data set (consisting of 5859 men and 1560 women) from a three-wave cohort study was used.

- Job stressors, work-to-family conflict (WFC) and psychological distress were observed, in this order, in the three waves, allowing us to examine how WFC mediated the associations between job stressors and psychological distress.

- The proportions of the association with psychological distress mediated by WFC were compared across eight types of job stressors.

- The study sample was dominated by men and was not population-representative, and unobserved individual attributes were not controlled for.

- High attrition rates, missing values in certain variables and no precise identification of the causality also limited the reliability of results.

association, focusing on specific job characteristics. For instance, the job demands-control (JD-C) model claims that workers with high job demands, low job control and/or their combination (high job strain) have a higher risk of psychological distress, ${ }^{12}$ while psychological distress itself has been shown to be a key factor for mortality from several major causes $^{3}$ as well as various health outcomes in preceding studies. The effort-reward imbalance (ERI) model claims that high effort, low reward and/or their combination (high ERI) lead to health risks. ${ }^{45}$ In recent years, more attention has been placed on the possibility that low levels of organisational justice, which refers to perceptions of fairness in treatment of the individuals within the workplace, may have an adverse impact on employee health outcomes. ${ }^{6} 7$

In addition to these job stressors faced by employees in the workplace, work-family conflict has been shown to have an adverse 
association with employee mental health, specifically in terms of psychological distress, mental disorders and depression. ${ }^{8-24}$ Employees often face conflict in responsibilities and obligations between the workplace and family life, which are likely to spill over into other domains, resulting in adverse impacts on mental health. ${ }^{13} 23$ Work-family conflict can be divided into two forms: workto-family conflict (WFC; workplace demands interfering with family responsibilities) and family-to-work conflict (FWC; family obligations interfering with work responsibilities) ${ }^{16}$ In any case, work-family conflict, regardless of whether WFC or FWC, is not an exogenous variable because it is likely affected by stressors in either the workplace or family life. ${ }^{819}$

Work-family conflict has attracted more attention in Japan as well as in other advanced countries. The official labour statistics ${ }^{25}$ show that the employment/population ratio among women aged 15-64 years old has been increasing substantially in recent years (from $51.5 \%$ in 1980 to $66.1 \%$ in 2016), although the ratio is somewhat lower than that in many European countries. The ratio of full-time employees is much lower among women than among men (women: $56.1 \%$ vs men: $88.9 \%$ in 2016 ) and managerial positions are still dominated by men $(87.1 \%$ in 2016). However, delayed adjustment of social policy and corporate management to an increase in women's labour force participation, along with traditional gender norms, has made it more difficult to balance work and family life. ${ }^{26}$ Correspondingly, an increasing number of studies have been addressing work-family conflict and its relevance to health using Japanese data (eg, refs 9 21-23).

In the present study, we hypothesised that WFC would mediate the associations between job stressors and employee psychological distress, and examined this hypothesis using data from a three-wave panel collected at 1-year intervals. These data were obtained from an occupational cohort study in Japan (Japanese Study of Health, Occupation, and Psychosocial Factors Related Equity; J-HOPE). We focused on WFC, rather than on FWC, because the former seems to have implications that are more practical for health promotion in the workplace than the latter does. In examining the mediating effect of WFC on the associations between job stressors and psychological distress, we compared the results across eight types of job stressors, which were divided into the following three groups: (1) job demands, job control and job strain (based on the JD-C model); (2) effort, reward and ERI (based on the ERI model); and (3) procedural justice and interactional justice (two major types of organisational justice). High job demands and effort may reduce disposable resources for family life, resulting in a spillover of the negative load effects. This effect is likely to raise WFC, which in turn results in increased psychological distress. Low job control and reward, which mean limited job resources, are expected to have psychological impacts that are different from those caused by high job demands and effort because they are not necessarily accompanied by a trade-off between workplace and family life. Meanwhile, organisational justice, which can be considered another domain of job resources, may affect employees' management of the integration of their work and family lives, ${ }^{18}$ possibly in a way that is different from that of job stressors. Some studies have addressed the mediating effect of WFC, but have focused on specific job stressors such as job demands, ${ }^{22} \mathrm{ERI}^{11}$ or organisational justice, ${ }^{15}$ leaving the relative importance of the mediating effect for each job stressor unclear.

We also considered gender differences in the mediating effects of WFC between job stressors and employee psychological distress. Preceding studies that have observed gender differences in the association between WFC and health have likely reflected differences in the balance between work and family life between men and women. ${ }^{91417}$ However, the evidence for the gender difference in the levels of WFC or the strength of the association between WFC and health has been mixed. ${ }^{8}$ Men participate more in the labour force and are more likely to be engaged in full-time work compared with women, while women tend to have greater difficulties with combining work and private life compared with men, probably leading to mixed observation of gender differences. ${ }^{14}$ In addition, cross-country studies ${ }^{9} 18$ suggest that these gender differences are affected by the sociocultural background as well, especially in terms of labour participation and gender egalitarianism in workplace, as well as roles played in and obligations pertaining to family life.

To conduct the mediation analysis, we used data from a three-wave panel, with a 1-year interval, obtained from J-HOPE. Job stressors, WFC and psychological distress were observed at baseline, 1-year follow-up and 2-year follow-up, respectively, allowing us to alleviate simultaneity biases. We computed the proportion of the total association between each job stressor and psychological distress, as mediated by WFC, within the framework of the mediation analysis. ${ }^{27}{ }^{28}$ In these statistical analyses, we controlled for key covariates, including job types and hours worked, which were expected to confound the associations examined.

\section{METHODS \\ Design}

This study was a confirmatory data analysis to examine the validity of the hypothesis that WFC would mediate the associations between the job stressor and employee psychological distress, considering eight types of job stressors. To this end, we used panel data from four waves (waves 1-4) of J-HOPE, which collected data of employees working in 13 surveyed firms, 3 of which participated only in the first three waves. The surveyed firms covered 12 types of industries, including manufacturing, transportation and information technology. Wave 1 was conducted between October 2010 and December 2011 (depending on the availability of firms), and the following waves (waves 2-4) were conducted approximately 1 year following the first, in each firm. The questions about job stressors and 
Table 1 The structure of the three-wave cohort data set used in the analysis*

\begin{tabular}{|c|c|c|c|c|c|c|}
\hline Firm code (industry) & Wave 1 & Wave 2 & Wave 3 & Wave 4 & Men & Women \\
\hline 1 (Information technology) & & JS & WFC & PD & 470 & 115 \\
\hline 2 (Manufacturing) & & JS & WFC & PD & 1687 & 200 \\
\hline 5 (Pharmaceutical) & & JS & WFC & PD & 135 & 141 \\
\hline 6 (Service) & & JS & WFC & PD & 9 & 16 \\
\hline 8 (Medical facilities) & & JS & WFC & PD & 10 & 14 \\
\hline 9 (Service) & & JS & WFC & PD & 281 & 117 \\
\hline 10 (Manufacturing) & JS & WFC & PD & & 1931 & 697 \\
\hline 11 (Transportation) & & JS & WFC & PD & 887 & 38 \\
\hline 13 (Real estate) & JS & WFC & PD & & 50 & 27 \\
\hline
\end{tabular}

${ }^{*}$ Data of participants in firm 3 (manufacturing) and 12 (real estate) were not used due to lack of availability of a full set of three-wave data. JS, job stressors; PD, psychological distress; WFC, work-to-family conflict.

psychological distress were asked in all waves, while those about WFC were asked only in waves 1 and 2. We used the data of participants from 11 firms, who provided a full set of responses to the questions about job stressors at baseline, WFC at 1-year follow-up and psychological distress at 2-year follow-up. The baseline corresponded to wave 1 for two firms and to wave 2 for nine firms. The participants in the remaining two firms were excluded because a full set of three-wave data was not available. The data structure is summarised in table 1.

\section{Participants}

The original sample consisted of $10753,11405,10977$ and 6553 participants in waves 1, 2, 3 and 4, respectively. In wave 1, all employees (13965 individuals in total) who were working in each of the 13 surveyed firms were invited to participate in the study through their firms' personnel sections, and 10773 individuals responded (response rare: $77.0 \%$ ). The attrition rates were $18.3 \%, 13.2 \%$ and $16.5 \%$ in waves 2,3 and 4 , respectively. The response rates for the questions on WFC, job stressors and psychological distress were relatively high, ranging between $94.8 \%$ (for ERI) and 96.9\% (for WFC). After excluding participants with missing values in key covariates, we eventually used the data on 7419 individuals (5859 men and 1560 women), representing $85.4 \%$ of the entire 8684 participants (6105 men and 2589 women) at baseline.

\section{Measures}

Work-to-family conflict

Following Chandola et $a l^{9}$ eight questions concerning work-family conflicts were constructed: four for FWC and four for WFC. We used the Japanese version of the WFC questionnaire that has been used in preceding studies. ${ }^{921}$ The participants were asked 'To what extent do your job responsibilities interfere with your family life?' and the following four items pertained to WFC: (1) 'your job reduces the amount of time you can spend with the family',
(2) 'problems at work make you irritable at home', (3) 'your work involves a lot of travel away from home' and (4) 'your job takes so much energy that you don't feel up to doing things that need attention at home'. These items were rated on a 3-point scale (1=not at all, 2=to some extent and 3=a great deal). The Cronbach's alpha coefficient for the WFC questionnaire was 0.60 in the present sample. We summed these item scores (range: 4-12), with higher scores indicating a higher level of conflict. Next, we constructed a binary variable for high WFC, in which scores equal to or higher than the median of the entire sample (seven) were assigned the value of 1 , and those below the median were assigned the value of 0 .

\section{Psychological distress}

We used the Kessler 6 (K6) scores ${ }^{29} 30$ as an indicator of psychological distress. The validity of the Japanese version of the K6 questionnaire has been confirmed. ${ }^{31}$ From J-HOPE, we first obtained participant assessments of psychological distress using the following six-item psychological distress question: 'During the past 30 days, about how often did you feel a) nervous, b) hopeless, c) restless or fidgety, d) so depressed that nothing could cheer you up, e) that everything was an effort and f) worthless', where each item was rated on a 5 -point scale $(0=$ none of the time to $4=$ all of the time). Subsequently, we calculated the sum of the reported scores (range: 0-24) and defined it as the K6 score. Higher K6 scores reflected higher levels of psychological distress. The Cronbach's alpha coefficient for the K6 was 0.90 in the present sample. We then constructed a binary variable for psychological distress, defined as a $\mathrm{K} 6 \geq 5$, which has been found to indicate $\mathrm{mood} /$ anxiety disorder in a Japanese sample. ${ }^{32}$

Job demands and control

We constructed three binary variables indicating high job demands, low job control and high job strain based on the JD-C model. ${ }^{33}$ To this end, we used the items 
investigating job demands and control from the Japanese version of the Job Content Questionnaire (JCQ), the validity of which has been confirmed. ${ }^{34}$ The JCQ is based on the JD-C model and includes scales related to job demands (five items) and job control (nine items), rated on a 4-point scale (1=strongly disagree to $4=$ strongly agree). In the present sample, the Cronbach's alpha coefficients were 0.70 and 0.77 for the job demands and control scales, respectively. We summed the responses to these items into single indices of job demands (range: 12-48) and control (range: 24-96). We also calculated the job demands/control ratio to measure the extent of job strain. Finally, we conducted the median-split method on the score of each category, classifying each worker as either high or low.

\section{Effort and reward}

To assess effort and reward based on the ERI model, ${ }^{35}$ we used the data that were collected using a simplified Japanese version of the Effort-Reward Imbalance Questionnaire (ERIQ), the validity of which has been confirmed. ${ }^{36}$ The ERIQ was developed based on the ERI model, and the simplified ERIQ was used in the present study. The questionnaire included subscales on effort (three items) and reward (seven items), rated on a 4-point scale (1=strongly disagree to $4=$ strongly agree $)$. Cronbach's alpha coefficients were 0.78 and 0.77 for the effort and reward scales, respectively. We summed the responses into single indices for effort (range: 3-12) and reward (range: 7-28). To measure the extent of ERI, we also calculated the effort/reward ratio and adjusted for differences between the two items. Subsequently, we used the median-split method to construct binary variables.

\section{Procedural and interactional justice}

We measured the procedural and interactional aspects of organisational justice using the Japanese version of the Organisational Justice Questionnaire (OJQ), ${ }^{37} 38$ the validity of which has been confirmed. ${ }^{39}$ The OJQ comprises a seven-item scale measuring procedural justice and a six-item scale measuring interactional justice, both rated on a 5-point Likert scale (1=strongly disagree to $5=$ strongly agree). In this sample, the Cronbach's alpha coefficients were 0.90 and 0.95 for procedural and interactional justice scales, respectively. For each justice type, we summed all item scores and divided that number by the number of items in that category, yielding a variable with a score ranging from 1 to 5 . Then, we used the median-split method to construct binary variables indicating low procedural and interactional justice.

\section{Covariates}

We used age, educational attainment (high school or below, junior college, college and graduate school), nine job types (eg, manager, clerk and factory worker), hours worked per week, household income (adjusted for household size by dividing the root of the number of household members), having one or more family member to share living expenses, 12 firm codes and the indicator variables of firms.

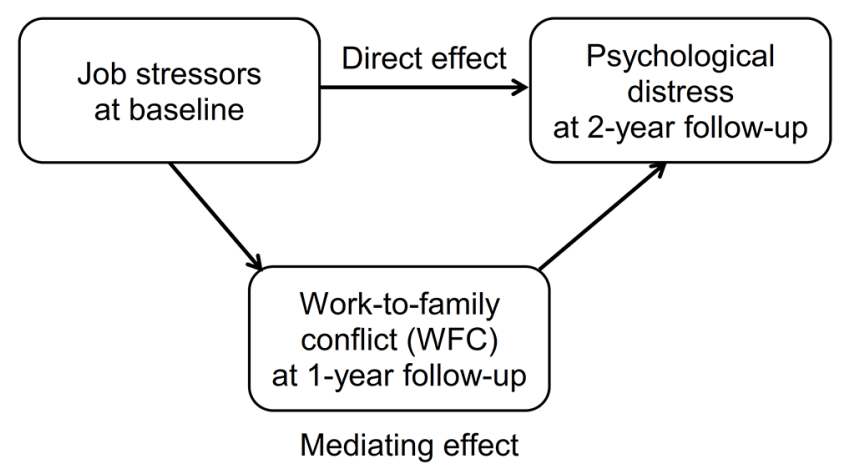

Figure 1 Conceptual framework of the mediation analysis.

\section{Statistical analysis}

We conducted mediation analysis ${ }^{27} 28$ to examine the mediating effect of WFC, as illustrated in figure 1, using data on job stressors, WFC and psychological distress observed at baseline, 1-year follow-up and 2-year follow-up, respectively. Specifically, following Baron and Kenny, ${ }^{40}$ we estimated three logistic regression models: model 1 to explain psychological distress by each job stressor, model 2 to explain WFC by each job stressor and model 3 to explain psychological distress by each job stressor and by WFC, along with a set of the same covariates observed at baseline. If models 1, 2 and 3 show significant and positive associations between the job stressor and psychological distress, between job stressors and WFC, and between WFC and psychological distress, respectively, then we can suspect that WFC mediates the association between job stressors and psychological distress. We evaluated statistical significance at the $5 \%$ level, and expressed the associations in terms of the odds ratio (OR) and 95\% confidence interval (CI). Furthermore, we implemented bootstrapping to assess the significance of the mediating effect $^{27} 284142$ : we computed the proportion of the total association between each job stressor and its $95 \% \mathrm{CI}$ obtained by bootstrap estimation with 2000 replications. If the computed $95 \%$ CI includes 0 , we can argue that the mediating effect of WFC is significant at the $5 \%$ level. To deal with the potential problem related to multiple comparisons, we additionally examined the significance of the mediating effect of WFC based on the $99.375 \%$ CI, which corresponded to the Bonferroni-corrected alpha level, $0.625 \%(=5 \% / 8)$, as we conducted the tests for eight types of job stressors. We performed this mediation analysis separately for men and women. We calculated the achieved power (with $\alpha=0.05$, two-tailed) for each job stressor and WFC in each model using the actual sample sizes. ${ }^{43}$

\section{RESULTS}

Key sample features at baseline are presented in table 2. Men had a higher educational attainment, worked longer and earned higher income. There were gender differences in the types of job as well; notably, the proportions of managerial workers, engineers and technicians were 
Table 2 Basic sample features at baseline wave

\begin{tabular}{|c|c|c|c|c|c|}
\hline & \multicolumn{2}{|c|}{ Men } & \multicolumn{2}{|c|}{ Women } & \multirow[t]{2}{*}{ Difference (men - women) } \\
\hline & $\mathbf{M}$ & (SD) & $\mathbf{M}$ & (SD) & \\
\hline Age (years) & 40.9 & $(10.3)$ & 39.7 & $(9.8)$ & $1.3^{*}$ \\
\hline Hours worked per week & 44.6 & $(10.2)$ & 34.4 & $(13.2)$ & $10.2^{*}$ \\
\hline Junior high school & 42.0 & & 49.3 & & $-7.3^{*}$ \\
\hline Junior college & 12.3 & & 26.6 & & $-14.3^{*}$ \\
\hline College & 32.7 & & 20.5 & & $12.2^{*}$ \\
\hline Graduate school & 13.1 & & 3.7 & & $9.4^{*}$ \\
\hline \multicolumn{6}{|l|}{ Job classification } \\
\hline Engineers and technicians & 13.2 & & 2.4 & & $10.8^{*}$ \\
\hline Clerical workers & 8.3 & & 33.4 & & $-25.1^{\star}$ \\
\hline Service workers & 3.8 & & 2.4 & & $1.3^{* *}$ \\
\hline Manufacturing workers (technical) & 9.0 & & 2.4 & & $6.6^{\star}$ \\
\hline Manufacturing workers (operational) & 13.5 & & 5.4 & & $8.1^{*}$ \\
\hline Manufacturing workers (manual) & 6.3 & & 17.0 & & $-10.7^{\star}$ \\
\hline Other & 11.3 & & 21.3 & & $-10.0^{*}$ \\
\hline Having one or more family member & 20.3 & & 20.6 & & -0.3 \\
\hline
\end{tabular}

${ }^{\star} \mathrm{p}<0.001,{ }^{\star \star} \mathrm{p}<0.05$ (two-tailed).

higher among men, whereas those of clerical workers and manual manufacturing workers were higher among women. The proportions of educational attainment of college or graduate school (men; 45.7\%, women: $24.2 \%)$ were somewhat above the nationwide averages (men: $35.9 \%$, women: $22.7 \%$ in 2012) ${ }^{44}$ while the distribution based on job classification was largely similar to the nationwide distribution observed in the government statistics. $^{26}$

The results from the regression models (models 1-3) and the mediation analysis are presented in tables 3 and 4 , for men and women, respectively. For men, model 1 results showed that all types of job stressors were highly and positively associated with psychological distress. Model 2 results showed that most types of job stressors, except for job control, were highly and positively associated with WFC. Model 3 results showed that both job stressors and WFC were highly related to psychological distress. We also found that the OR of each job stressor (except for job control) was somewhat lower than that found in model 1 . These observations point to the partial mediating effect of WFC on the association between each job stressor and psychological distress, except for job control, which was negatively related to WFC, as shown in model 2. The rightmost column of table 3 presents the estimated proportion of the association between each job stressor (except for job control) and psychological distress mediated by WFC. The proportion of the mediating effect of WFC ranged from 9.1\% (95\% CI 3.8\% to 14.4\%) for procedural justice to $41.5 \%$ (95\% CI $31.4 \%$ to $51.7 \%$ ) for effort. The mediating effect of WFC was larger for job demands (39.1\% (95\% CI $29.1 \%$ to $49.1 \%)$ ) and effort (41.5\% (95\% CI $31.4 \%$ to $51.7 \%)$ ) than for other types of job stressors. The statistical significance of the mediating effect of WFC was confirmed for all job stressors even with wider $99.375 \%$ CIs, which took account of the multiple comparisons problem.

The results for women, which are presented in table 4, were largely similar to those for men, in that WFC mediated the association between each job stressor and psychological distress, except for job control, and that the mediating effect of WFC was the highest for job demands and effort. At the same time, we observed some gender differences by comparing the results between tables 3 and 4. First, model 1 showed no association between low job control and psychological distress in women, contrary to the positive association for men. Second, model 2 showed a closer association between each job stressor (except for job control) and WFC for women than that for men. Third, model 3 observed a closer association between 


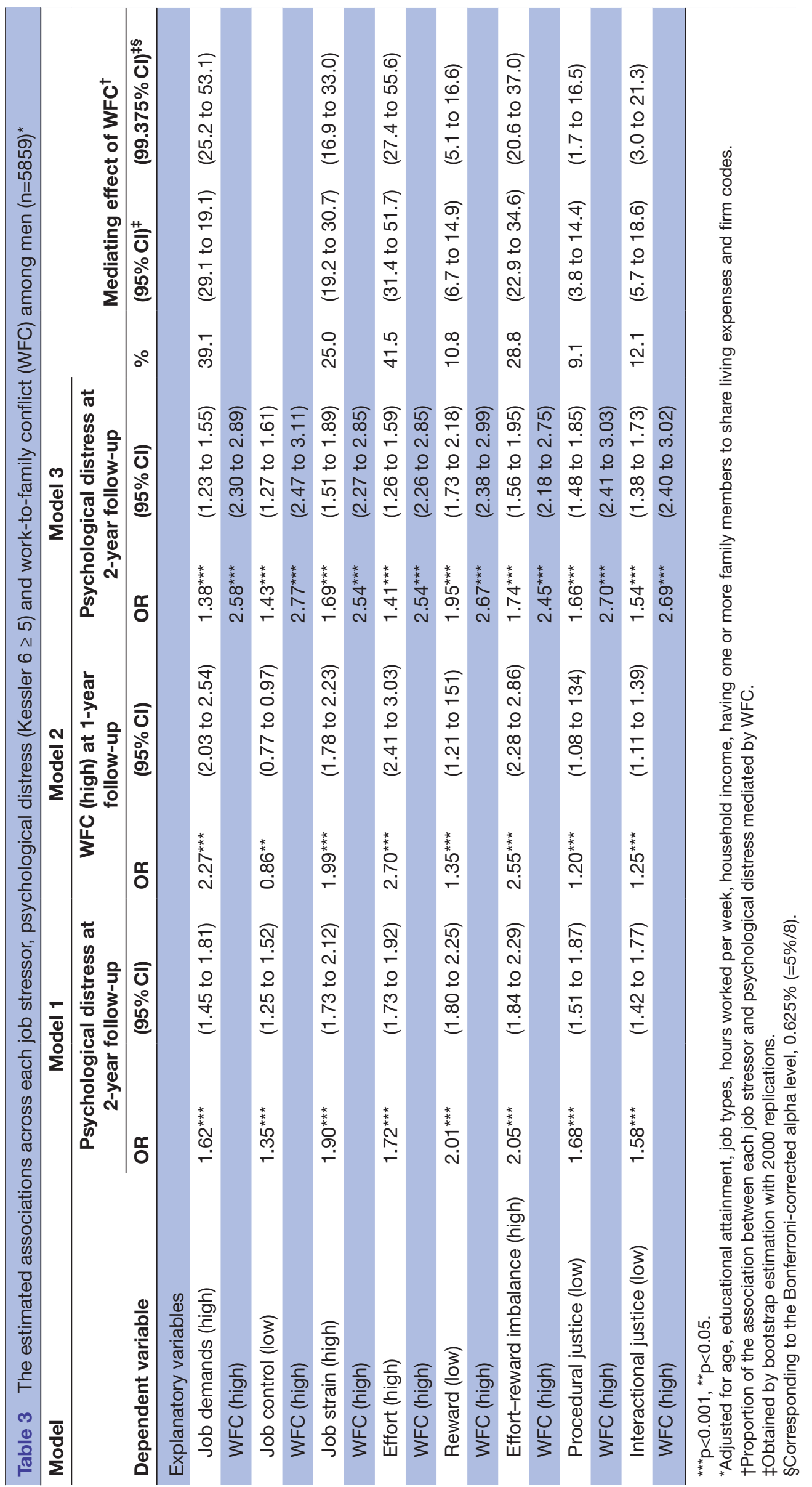




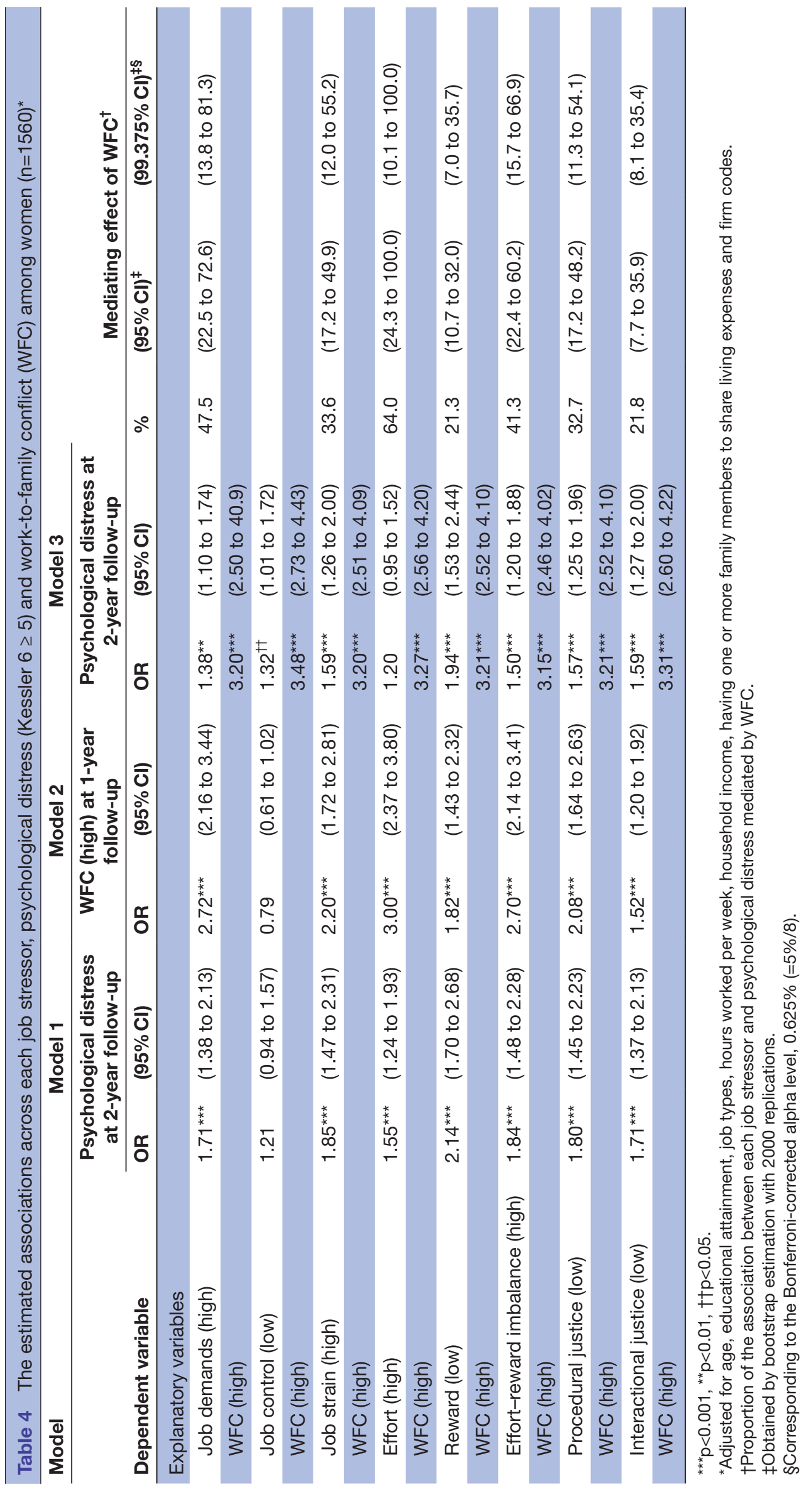


WFC and psychological distress for women than that for men. Finally, the mediating effect of WFC was somewhat larger for women than it was for men for all job stressors (except for job control), in line with a combination of the second and third observations.

We also found that the value of the achieved power was very close to one in most model specifications for both men and women; however, it was low in three cases for women (for job demands (0.41) in model 1 and for job control (0.65) and effort (0.40) in model 3), all of which corresponded to a non-significant or limited association with psychological distress.

\section{DISCUSSION}

We have examined the mediating effect of WFC on the association between job stressors and employee psychological distress using the panel data obtained from J-HOPE. As expected, and in line with what has been suggested by preceding studies, ${ }^{11} 1522$ the present results confirmed that WFC mediated the associations between job stressors and employee psychological distress. These findings are supportive of a view that the negative effect of stressful conditions in the workplace leads to an increased imbalance between work and family life, which in turn increases psychological distress.

In addition to this key result, the present study provided two noticeable findings, and both are expected to provide new insight into the understanding of the relevance of WFC. First, the mediating effect of WFC was higher for job demands and effort than it was for the other job stressors, which indicated reduced job resources. High levels of job demands and effort are likely to require employees to devote more resources to work, leaving them with fewer resources to devote to their family life, which may result in more WFC, and thus higher psychological distress. In this sense, higher WFC captures a trade-off between the responsibilities and obligations pertaining to work and family life, which is caused by the high job demands and effort. In comparison, the magnitude of the mediating effect of WFC tended to be smaller for job control, reward and organisational justice, which can be categorised as job resources. To be sure, the lower levels of these variables are likely to lead to fewer resources to devote to family life. However, they may not necessarily mean a serious trade-off between work and family life. Lower job control and reward may be accompanied by lower job demands and effort, and lower organisational justice does not directly cause fewer resources to devote to family life. In all, we can argue that job resources tend to be associated with employee psychological distress in a relatively direct manner, not mediated by WFC, as compared with that observed in the case of job demands and effort.

We also found that the mediating effect of WFC on the association between job stressors and psychological distress was somewhat larger for women than it was for men. Preceding studies have discussed gender differences in the associations between WFC and health outcomes, ${ }^{81316}$ but the gender differences in the mediating effects of WFC have been largely understudied. The present results suggest that stress in the workplace is more likely to be transformed to higher WFC for women than it is for men. It should be noted, however, that the study sample was highly male-dominated, even more than that suggested by the nationwide difference in the employment/population rates between men and women. This indicates the study sample's limited representativeness of all Japanese workers, requiring us to be cautious when making any generalisation. The results were also somewhat surprising given the shorter hours worked and lower proportions of jobs with high responsibility among women than among men in the present sample. However, the findings were generally supportive of the view that WFC is more relevant to the psychological distress of female employees in Japan. In recent decades, female labour force participation has been rising at such a fast pace in Japan that socioinstitutional settings do not seem to have been sufficiently adjusted to it. Put differently, we cannot rule out the possibility of obtaining different results about the gender differences in countries with already high levels of female labour force participation and family-friendly socioinstitutional settings.

We recognise several limitations and drawbacks in the present study, in addition to limited representativeness of the present male-dominant sample, the limited number of female participants, the arbitrary selection of types of firms and industries, and a somewhat low Cronbach's alpha coefficient for the WFC questionnaire $(0.60)$. First, we did not control for the potential biases that may arise due to the high attrition rates as well as exclusion of participants with missing data. In particular, results from auxiliary regressions (not reported) showed that participants who had reported higher levels of job stressors tended to drop out at the following wave, which points to the risk of underestimating the adverse impact of job stressors on psychological distress. Second, we disregarded FWC and stressors in family life. For a holistic understanding of the relevance of work-family conflict for employee health, we must expand the present analysis to cover FWC and stressors in family life as well. ${ }^{20-22}$ Third, we did not control for unobserved individual attributes such as personality traits. This may result in overestimated associations between job stressors and psychological distress, both of which were based on self-reported, subjective assessments. Lastly, it should be noted that we used a single point measure of each of independent, dependent and mediating variables obtained from a three-wave panel with a 1-year interval. We may obtain different results if we use their changes and/or choose a longer or shorter interval.

Despite these limitations, we can conclude that WFC acted as a key mediator in the association between most job stressors and employee psychological distress, especially for women. Results suggest that policy measures and the support of supervisors to prevent job stressors from 
adding to WFC are needed to reduce employee psychological distress.

Acknowledgements We used panel data from a four-wave survey of an occupational cohort study on social class and health in Japan (Japanese Study of Health, Occupation, and Psychosocial Factors Related Equity; J-HOPE), which was supported by a Grant-in-Aid for Scientific Research (KAKENHI) on Innovative Areas (Research in a Proposed Research Area) 2009-2013 (No 4102-21119001) from the Ministry of Education, Culture, Sports, Science and Technology, Japan.

Contributors T0 conducted the econometric analysis and drafted the original manuscript. AT managed the data collection. Al and AT contributed to the interpretation of the results and drafting of the article. All authors approved the final version.

Funding This work was supported by a Grant-in-Aid for Scientific Research (KAKENHI) from the Japan Society for the Promotion of Science, Grant Number 26245039.

Competing interests We have read and understood BMJ policy on declaration of interests and declare that we have no competing interests.

\section{Patient consent Obtained.}

Ethics approval The Research Ethics Committee of the Graduate School of Medicine and Faculty of Medicine, The University of Tokyo (No 2772), the Kitasato University Medical Ethics Organization (No B-12-103), and the Ethics Committee of the University of Occupational and Environmental Health, Japan (No 10-004).

Provenance and peer review Not commissioned; externally peer reviewed.

Data sharing statement There are no additional data available in relation to this manuscript. Contact the corresponding author (TO) if detailed information about the access to the data set is needed.

Open Access This is an Open Access article distributed in accordance with the Creative Commons Attribution Non Commercial (CC BY-NC 4.0) license, which permits others to distribute, remix, adapt, build upon this work non-commercially, and license their derivative works on different terms, provided the original work is properly cited and the use is non-commercial. See: http://creativecommons.org/ licenses/by-nc/4.0/

(c) Article author(s) (or their employer(s) unless otherwise stated in the text of the article) 2017. All rights reserved. No commercial use is permitted unless otherwise expressly granted.

\section{REFERENCES}

1. Karasek RA. Job Demands, Job Decision Latitude, and Mental Strain: Implications for Job Redesign. Adm Sci Q 1979;24:285-308.

2. Clays E, De Bacquer D, Leynen F, et al. Job stress and depression symptoms in middle-aged workers--prospective results from the Belstress study. Scand J Work Environ Health 2007;33:252-9.

3. Russ TC, Stamatakis E, Hamer M, et al. Association between psychological distress and mortality: individual participant pooled analysis of 10 prospective cohort studies. BMJ 2012;345:e4933.

4. Siegrist J. Adverse health effects of high-effort/low-reward conditions. J Occup Health Psychol 1996;1:27-41.

5. van Vegchel $\mathrm{N}$, de Jonge J, Bosma $\mathrm{H}$, et al. Reviewing the effortreward imbalance model: drawing up the balance of 45 empirical studies. Soc Sci Med 2005;60:1117-31.

6. Elovainio M, Kivimäki M, Helkama K. Organization justice evaluations, job control, and occupational strain. J Appl Psychol 2001;86:418-24.

7. Kivimäki M, Elovainio M, Vahtera J, et al. Organisational justice and health of employees: prospective cohort study. Occup Environ Med 2003;60:27-34.

8. Byron K. A meta-analytic review of work-family conflict and its antecedents. J Vocat Behav 2005;67:169-98.

9. Chandola T, Martikainen P, Bartley M, et al. Does conflict between home and work explain the effect of multiple roles on mental health? A comparative study of Finland, Japan, and the UK. Int J Epidemiol 2004;33:884-93.

10. Cooklin AR, Dinh H, Strazdins L, et al. Change and stability in workfamily conflict and mothers' and fathers' mental health: Longitudinal evidence from an Australian cohort. Soc Sci Med 2016;155:24-34.

11. du Prel JB, Peter R. Work-family conflict as a mediator in the association between work stress and depressive symptoms: cross- sectional evidence from the German lidA-cohort study. Int Arch Occup Environ Health 2015;88:359-68.

12. Frone MR, Russell M, Cooper ML. Relation of work-family conflict to health outcomes: A four-year longitudinal study of employed parents. J Occup Organ Psychol 1997;70:325-35.

13. Hammer LB, Cullen JC, Neal MB, et al. The longitudinal effects of work-family conflict and positive spillover on depressive symptoms among dual-earner couples. J Occup Health Psychol 2005;10:138-54.

14. Hämmig O, Bauer $\mathrm{G}$. Work-life imbalance and mental health among male and female employees in Switzerland. Int J Public Health 2009:54:88-95

15. Judge TA, Colquitt JA. Organizational justice and stress: the mediating role of work-family conflict. J Appl Psychol 2004;89:395-404.

16. Ernst Kossek E, Ozeki C. Work-family conflict, policies, and the job-life satisfaction relationship: A review and directions for organizational behavior-human resources research. J Appl Psychol 1998;83:139-49.

17. Leineweber C, Baltzer M, Magnusson Hanson LL, et al. Work family conflict and health in Swedish working women and men: a 2-year prospective analysis (the SLOSH study). Eur J Public Health 2013;23:710-6.

18. Lunau T, Bambra C, Eikemo TA, et al. A balancing act? Work-life balance, health and well-being in European welfare states. Eur J Public Health 2014;24:422-7.

19. McNall LA, Nicklin JM, Masuda AD. A Meta-Analytic Review of the Consequences Associated with Work-Family Enrichment. J Bus Psychol 2010;25:381-96.

20. Montgomery AJ, Peeters MCW, Schaufeli WB, et al. Work-home interference among newspaper managers: Its relationship with burnout and engagement. Anxiety, Stress \& Coping 2003;16:195-211.

21. Sekine M, Chandola T, Martikainen P, et al. Socioeconomic inequalities in physical and mental functioning of Japanese civil servants: explanations from work and family characteristics. Soc Sci Med 2006;63:430-45.

22. Shimazu A, Bakker AB, Demerouti E, et al. Work-family conflict in Japan: how job and home demands affect psychological distress. Ind Health 2010;48:766-74.

23. Shimazu A, Kubota K, Bakker A, et al. Work-to-family conflict and family-to-work conflict among Japanese dual-earner couples with preschool children: a spillover-crossover perspective. J Occup Health 2013:55:234-43.

24. Wang J, Afifi TO, Cox B, et al. Work-family conflict and mental disorders in the United States: cross-sectional findings from The National Comorbidity Survey. Am J Ind Med 2007;50:143-9.

25. Bureau S. Ministry of Internal Affairs and Communications. Labour Force Survey 2016. http://www.stat.go.jp/data/roudou/longtime/ 03roudou.htm (accessed 1 Apr 2017).

26. Cabinet Office. White Paper on gender equity. 2016. http://www. gender.go.jp/english_contents/about_danjo/whitepaper/index.html (accessed 1 Apr 2017)

27. MacKinnon DP. Introduction to statistical mediation analysis. New York, NY: Erlbaum, 2008

28. Mackinnon DP, Dwyer JH. Estimating Mediated Effects in Prevention Studies. Eval Rev 1993;17:144-58.

29. Kessler RC, Andrews G, Colpe LJ, et al. Short screening scales to monitor population prevalences and trends in non-specific psychological distress. Psychol Med 2002;32:959-76.

30. Kessler RC, Green JG, Gruber MJ, et al. Screening for serious menta illness in the general population with the $\mathrm{K} 6$ screening scale: results from the WHO World Mental Health (WMH) survey initiative. Int $J$ Methods Psychiatr Res 2010;19 Suppl 1:4-22.

31. Furukawa TA, Kawakami N, Saitoh M, et al. The performance of the Japanese version of the K6 and K10 in the World Mental Health Survey Japan. Int J Methods Psychiatr Res 2008;17:152-8.

32. Sakurai K, Nishi A, Kondo K, et al. Screening performance of K6/K10 and other screening instruments for mood and anxiety disorders in Japan. Psychiatry Clin Neurosci 2011;65:434-41.

33. Karasek R. Job Content Questionnaire and User's Guide. Lowell, MA: University of Massachusetts at Lowell, 1985.

34. Kawakami N, Kobayashi F, Araki S, et al. Assessment of job stress dimensions based on the job demands- control model of employees of telecommunication and electric power companies in Japan: reliability and validity of the Japanese version of the Job Content Questionnaire. Int J Behav Med 1995;2:358-75.

35. Siegrist J, Wege N, Pühlhofer F, et al. A short generic measure of work stress in the era of globalization: effort-reward imbalance. Int Arch Occup Environ Health 2009;82:1005-13. 
36. Kurioka S, Inoue A, Tsutsumi A. Optimum cut-off point of the Japanese short version of the effort-reward imbalance questionnaire. $J$ Occup Health 2014;55:340-8.

37. Elovainio M, Kivimäki M, Vahtera J. Organizational justice: evidence of a new psychosocial predictor of health. Am J Public Health 2002;92:105-8.

38. Moorman $\mathrm{RH}$. Relationship between organizational justice and organizational citizenship behaviors: Do fairness perceptions influence employee citizenship? J Appl Psychol 1991;76:845-55

39. Inoue A, Kawakami N, Tsutsumi A, et al. Reliability and validity of the Japanese version of the Organizational Justice Questionnaire. J Occup Health 2009;51:74-83.
40. Baron RM, Kenny DA. The moderator-mediator variable distinction in social psychological research: conceptual, strategic, and statistical considerations. J Pers Soc Psychol 1986;51:1173-82.

41. Hayes AF. Beyond Baron and Kenny: Statistical Mediation Analysis in the New Millennium. Commun Monogr 2009;76:408-20.

42. Hayes AF. Introduction to mediation, moderation, and conditional process analysis. New York: The Guilford Press, 2013.

43. Faul F, Erdfelder E, Buchner A, et al. Statistical power analyses using G*Power 3.1: tests for correlation and regression analyses. Behav Res Methods 2009;41:1149-60.

44. Ministry of Health, Labour and Welfare. Wage Census. 2017. http:// www.mhlw.go.jp/toukei/list/chinginkouzou.html (accessed 1 Apr 2017). 